\title{
Uso da metodologia de rotação por estações com a computação desplugada
}

\author{
Luciana P. de Araújo Kohler, Mauro M. Mattos, Heitor Ugarte, Leonardo Fronza, \\ Bruno F. F. Santos, Liz Rios Largura, Fabrícia D. Zucco, Andrea Wuo \\ ${ }^{1}$ Laboratório de Desenvolvimento e Transferência de Tecnologias (LDTT) \\ Universidade Regional de Blumenau (FURB) \\ Blumenau - SC - Brasil. \\ \{mattos, lpa, hucsilveira, leofronza, bffsantos\}@furb.br \\ \{lrlargura, fabricia, wuo\}@furb.br
}

\begin{abstract}
With purpose to introduce the computational thinking in the elementary school, the extension project developed a circuit with four stations containing activities related to computational thinking. As some schools do not have informatic lab until the application of the circuit, it was decided working with the unplugged computing. The circuit was applied in five classes of two different schools. After all ludic activities, it is understand that the children was developed some abilities of computational thinking.
\end{abstract}

Resumo. Com o objetivo de introduzir o pensamento computacional no ensino fundamental, realizou-se uma atividade de rotação por estações contendo atividades relacionadas ao pensamento computacional. Como algumas escolas não possuíam laboratório até o momento da aplicação da atividade, decidiu-se trabalhar com a computação desplugada. A atividade foi aplicada em quatro turmas de duas escolas diferentes. Após todas as atividades lúdicas realizadas, percebeu-se que as crianças conseguiram desenvolver algumas das habilidades do pensamento computacional.

\section{Introdução}

O termo Pensamento Computacional (PC), introduzido em [Wing 2006], é um método para ensinar a solucionar problemas, conceber sistemas e compreender o comportamento humano inspirando-se em conceitos da Ciência da Computação ou, como colocado por [de Paula et al. 2014], "é uma maneira específica de se pensar e de analisar uma situação ou um artefato, sendo independente do uso da tecnologia". Assim, desenvolver habilidades em PC não significa necessariamente aprender a programar [Zanetti et al. 2016].

As três habilidades básicas que fundamentam o PC são: abstração, automação e análise. A habilidade de abstração está associada a capacidade de o indivíduo extrair apenas as características mais importantes de um problema para chegar a uma solução. A habilidade de automção está associada a capacidade de utilização de algum meio eletrônico que pode substituir o trabalho de um ser humano e a habilidade de análise está associada ao estudo dos resultados gerados pela automação [Zanetti et al. 2013].

Nesse contexto também encontra-se a computação desplugada. A computação desplugada é um método educacional para ensinar conceitos de computação sem o uso 
VIII Congresso Brasileiro de Informática na Educação (CBIE 2019)

Anais dos Workshops do VIII Congresso Brasileiro de Informática na Educação (WCBIE 2019)

de computadores e/ou tecnologias e normalmente é utilizado para ensinar pessoas que não são especialistas em computação, sendo bem aplicado no âmbito infantil e escolar [Nishida et al. 2009].

Nesse sentido, este relato de experiência refere-se a uma atividade realizada em um projeto de extensão que tem como objetivo introduzir o pensamento computacional nos anos inicias ( $2^{\circ}$ ao $5^{\circ}$ ano do ensino fundamental) em escolas públicas do município de Blumenau, Santa Catarina. Para introduzir conceitos de pensamento computacional, propôs-se uma atividade com quatro estações utilizando a metodologia de rotação por estações com diferentes práticas de computação desplugada as quais são relatadas a seguir.

$\mathrm{O}$ artigo segue dividido da seguinte forma. A seção 2 descreve a metodologia adotada, bem como relata as quatro estações da metodologia de rotação. A seção 3 discute os resultados obtidos com a prática. Por fim, a seção 4 descreve sobre as considerações finais.

\section{Metodologia e Estações}

Com o objetivo de introduzir questões do pensamento computacional sem o uso do computador, criou-se uma atividade de rotação por estações com quatro estações contendo atividades relacionadas as habilidades do pensamento computacional. Para a concepção das atividades, utilizou-se como base as definições curriculares do Centro de Inovação para a Educação Brasileira (CIEB) [CIEB 2018]. Para metodologias de aplicação e inspiração das atividades utilizou-se o trabalho de [Guarda et al. 2018] que realizou um circuito com 4 desafios para turma de ensino fundamental, focado na área de problemas matemáticos.

Sabendo-se que após a introdução com a computação desplugada seriam aplicadas oficinas envolvendo uma ferramenta para o desenvolvimento de habilidades relacionadas a programação, a qual foi desenvolvida pelo projeto de extensão em questão, as atividades desenvolvidas foram projetadas pensando no uso posterior desta ferramenta para que os alunos realizassem uma correlação com a mesma.

A atividade foi realizada com quatro turmas diferentes do ensino fundamental, sendo as turmas do $2^{\circ}$ ao $5^{\circ}$ ano da escola Pedro II. A atividade ocorreu durante 1 hora e 30 minutos com cada uma das turmas, durante seu período letivo de aula, de modo que todos os alunos das turmas participaram da atividade. As turmas eram compostas por uma média de 20 alunos, de modo que em cada estação e trabalhavam cerca de 5 alunos de forma simultânea. Cada estação teve duração aproximada de 20 minutos. Os 30 minutos restantes foram utilizados para troca de uma estação para outra e para uma reflexão ao final da atividade.

Na metodologia de rotação por estações são definidas estações com atividades específicas. Os alunos participantes são divididos igualmente em grupos para ocupar cada uma das estações. Após certo período de tempo, neste caso 20 minutos, os alunos são rotacionados de atividade. Dessa forma, todos os alunos podem participar de todas as atividades propostas.

As atividades foram alocadas em três espaços diferentes sendo duas salas de aula e um pátio. Dessa forma, as crianças puderam se acomodar bem em cada uma das estações, sem que uma atividade atrapalhasse a outra. Em cada estação ficaram 2 monitores para controlar as atividades, tirar dúvidas e realizar as anotações referentes ao aprendizado 
VIII Congresso Brasileiro de Informática na Educação (CBIE 2019)

Anais dos Workshops do VIII Congresso Brasileiro de Informática na Educação (WCBIE 2019)

da atividade em relação ao Pensamento Computacional. Antes de iniciar a atividade, as estações foram explicadas para todos os participantes, contudo, sempre ao iniciar a estação a atividade era relembrada para orientar os participantes.

Assim, as quatro atividades foram: jogo de tabuleiro com cartas; jogo de tabuleiro vivo; ordenação de cartas; e, identificação de bug. As atividades são explanadas na Tabela 1 e em seguida são apresentadas com detalhes em cada uma das subseções seguintes.

Tabela 1. Atividades de rotação por estações

\begin{tabular}{|c|c|c|c|}
\hline Desafio & Descrição & $\begin{array}{l}\text { Material } \\
\text { utilizado }\end{array}$ & Habilidades do PC \\
\hline $\begin{array}{l}\text { Tabuleiro } \\
\text { com cartas }\end{array}$ & $\begin{array}{l}\text { Sair de uma posição de } \\
\text { origem e chegar até o } \\
\text { destino utilizando comandos } \\
\text { de programação sequencial. }\end{array}$ & $\begin{array}{l}\text { Tabuleiro de } \\
\text { papel, peões e } \\
\text { cartas }\end{array}$ & $\begin{array}{l}\text { Abstração; } \\
\text { Análise de dados; } \\
\text { Algoritmos; } \\
\text { Decomposição. }\end{array}$ \\
\hline $\begin{array}{l}\text { Tabuleiro } \\
\text { vivo }\end{array}$ & $\begin{array}{l}\text { Utilizar da estratégia de jogo } \\
\text { para completar os objetivos } \\
\text { conforme cada personagem. }\end{array}$ & $\begin{array}{l}\text { Tiaras de papel e } \\
\text { um dado }\end{array}$ & $\begin{array}{l}\text { Abstração; } \\
\text { Algoritmos. }\end{array}$ \\
\hline $\begin{array}{l}\text { Sequência } \\
\text { de cartas }\end{array}$ & $\begin{array}{l}\text { Identificar a ordem correta } \\
\text { de uma atividade do cotidiano. }\end{array}$ & Folha A4 & $\begin{array}{l}\text { Abstração; } \\
\text { Decomposição; } \\
\text { Reconhecimento de } \\
\text { padrões. }\end{array}$ \\
\hline $\begin{array}{l}\text { Identificação } \\
\text { de bugs }\end{array}$ & $\begin{array}{l}\text { Identificar o erro a partir de } \\
\text { uma sequência de } \\
\text { atividade do cotidiano. }\end{array}$ & Folha A4 & $\begin{array}{l}\text { Abstração; } \\
\text { Decomposição; } \\
\text { Reconhecimento de } \\
\text { padrões. }\end{array}$ \\
\hline
\end{tabular}

\subsection{Jogo de tabuleiro}

O jogo tabuleiro com cartas foi produzido pela equipe do projeto. Este jogo possui um tabuleiro dividido em linhas e colunas, conforme apresentado na Figura 1. No centro do tabuleiro podem conter cenários diferentes, com objetivos diferentes. Neste exemplo, tem-se paredes que são obstáculos e um tesouro no centro que é o ponto de chegada. $O$ tabuleiro possui quatro saídas, sendo representadas pelos peões. Contudo, se tiver mais de quatro jogadores, dois jogadores podem sair do mesmo ponto de partida. Abaixo de cada um desses pontos de partida há uma rosa dos ventos, indicando as direções do tabuleiro, sendo: norte, sul, leste e oeste.

Além do tabuleiro, existem cartas que contém um comando de programação, sendo elas: andarNorte() ; andarSul() ; andarLeste(); e andarOeste ( ) ; , bem como cartas coringas com os comandos "trocar as cartas com o colega da direita", "todos trocam as cartas" e "trocar as cartas com o monte". Essas cartas são utilizadas pelos jogadores para fazer com que o peão se movimente pelo cenário.

Cada jogador recebe cinco cartas e, na sua vez, pode utilizar até 3 cartas para realizar a movimentação do seu peão. Após utilizar as cartas, as mesmas ficam posicionadas em sua frente de modo a representar as cartas utilizadas para o movimento até o momento. Em seguida, o jogador deve comprar as cartas do monte para manter sempre cinco cartas 
VIII Congresso Brasileiro de Informática na Educação (CBIE 2019)

Anais dos Workshops do VIII Congresso Brasileiro de Informática na Educação (WCBIE 2019)

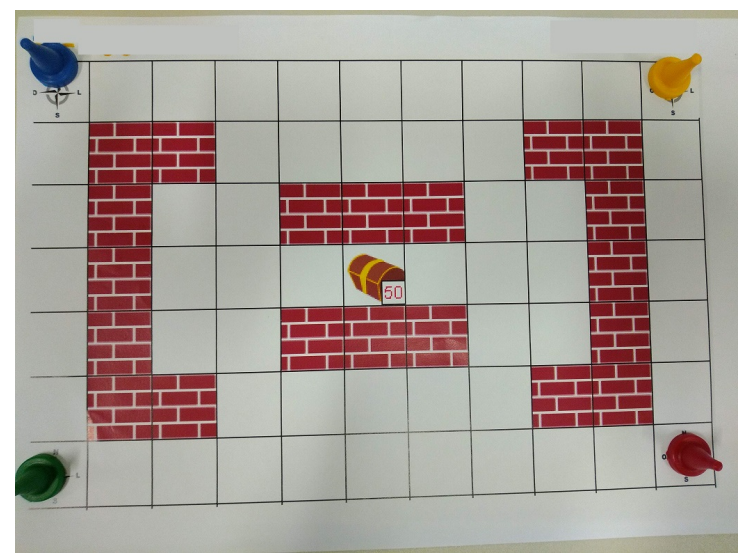

Figura 1. Tabuleiro

na mão. O jogo segue para o outro jogador realizar o mesmo processo e assim sucessivamente. Quando o primeiro jogador chegar no objetivo ganha o jogo. Caso o jogador não tenha como jogar, em sua vez ele pode trocar até três cartas de sua mão com as cartas do monte da mesa.

Ao completar o objetivo, o jogador deve possuir em sua frente todas as cartas utilizadas para o desenvolvimento da atividade, isto é, quais comandos utilizou para sair da posição de origem e chegar até a posição de destino. Para verificar se o jogador completou a tarefa corretamente, o monitor confere os passos reiniciando o peão da posição de origem e andando com ele pelo tabuleiro de acordo com as cartas utilizadas pelo jogador. Realizando este processo, o aluno é introduzido a alguns conceitos do pensamento computacional, como: sequência de instruções (as cartas utilizadas devem ser lidas em uma sequência); algoritmo (a junção das cartas formam um algoritmo a ser interpretado e executado quantas vezes forem necessárias); identificação de que o computador só realiza o que foi executado, isto é, o peão só poderá se movimentar se foi indicado o comando a partir da carta para ele.

Nessa atividade foram coletadas informações a respeito das jogadas dos jogadores e da sua evolução ao longo das rodadas. Isto é, observou-se se o jogador jogava a melhor carta de sua mão, se não executava movimentos repetitivos, como por exemplo andarNorte () e em seguida andarSul () que faria com que o jogador permanecesse no mesmo local, entre outras situações de jogo. Essa coleta foi feita a partir da observação direta e de anotações durante as jogadas e foi utilizada para comparar a evolução dos jogadores ao longo das rodadas.

\subsection{Jogo de tabuleiro vivo}

O jogo de tabuleiro vivo é semelhante ao jogo de tabuleiro com cartas. Ele é constituído de um tabuleiro grande com linhas e colunas, sendo que os peões são representados pelos próprios jogadores. Nesse jogo devem participar cinco jogadores, contudo, podem haver variações para número de participantes diferenciado. Na Figura 2 tem-se o modelo do tabuleiro vivo. Nos cantos tem-se a representação de um robô e no centro do tabuleiro um tesouro. Nessas representações devem se posicionar os jogadores.

Ainda, cada jogador recebe uma tiara para colocar na cabeça indicando seu personagem no jogo. Os jogadores das bordas são denominados de Robô e o jogador do centro 


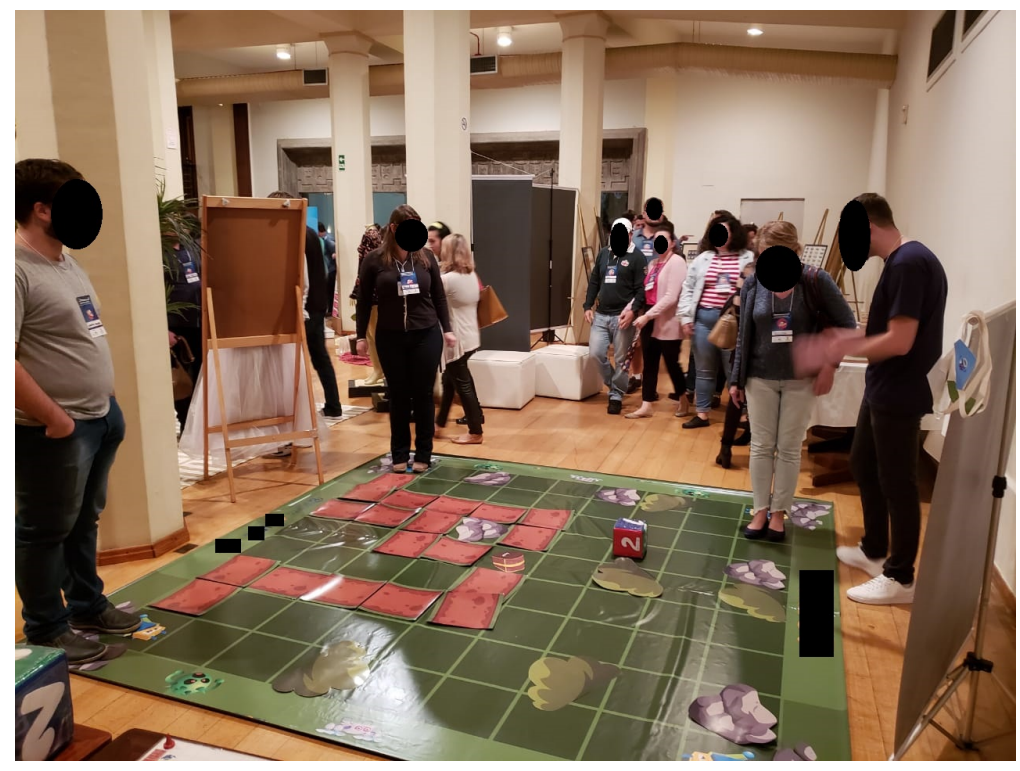

Figura 2. Tabuleiro Vivo

é denominado de Alien. O objetivo dos robôs é chegar até o tesouro e o objetivo do Alien é pegar o robô. Caso o Alien toque em um robô, este vira também um Alien e ajuda a pegar os outros robôs. Caso um robô chegue no centro do mapa, ele vira um Anjo e então sua missão é salvar um Alien. Após salvar o Alien, o jogador Anjo e o Alien salvo voltam a ser robôs. O jogo finaliza quando todos são Aliens ou todos são robôs.

Para se movimentar pelo cenário, na sua vez, o jogador deve jogar o dado e andar pelo tabuleiro a quantidade de passos correspondentes ao valor do dado. O jogador não pode se movimentar na diagonal, sendo os passos possíveis os equivalentes a atividade anterior. $\mathrm{O}$ dado contém dois números 1 , dois números 2 , um número 3 e um número 0 . Caso o jogador tirar o número 0 , ele passa a vez para outro jogador. Como dois jogadores não podem ocupar a mesma célula do tabuleiro, a ação de pegar o outro jogador conta como uma jogada. Dessa forma, um jogador que tirar o número 3 pode andar duas casas e utilizar a terceira jogada para pegar o jogador. Para pegar um jogador, este deve estar em uma célula adjacente a célula em que o jogador da vez se encontra.

A Figura 3 apresenta as crianças jogando durante a atividade realizada. Neste momento, ainda não existia o tabuleiro de lona em sua forma física, sendo que as células eram representadas pelos azulejos quadrados do pátio da escola. Ainda, o tabuleiro era delimitado por uma corda. Na figura também observa-se as crianças utilizando as tiaras com a identificação de seus personagens.

Além das habilidades de pensamento computacional que envolviam a atividade, a criança é estimulada a criar estratégias de jogo e a pensar antes de agir, pois com base em seus movimentos ela poderá ganhar ou perder o jogo.

Nesta atividade foram coletadas informações a respeito das jogadas executadas pelo jogadores no tabuleiro, bem como sobre as decisões estratégicas tomadas. A coleta também foi feita por meio da observação direta e de anotações, para posteriormente ser utilizada para identificar a evolução dos jogadores ao longo das rodadas. 
VIII Congresso Brasileiro de Informática na Educação (CBIE 2019)

Anais dos Workshops do VIII Congresso Brasileiro de Informática na Educação (WCBIE 2019)

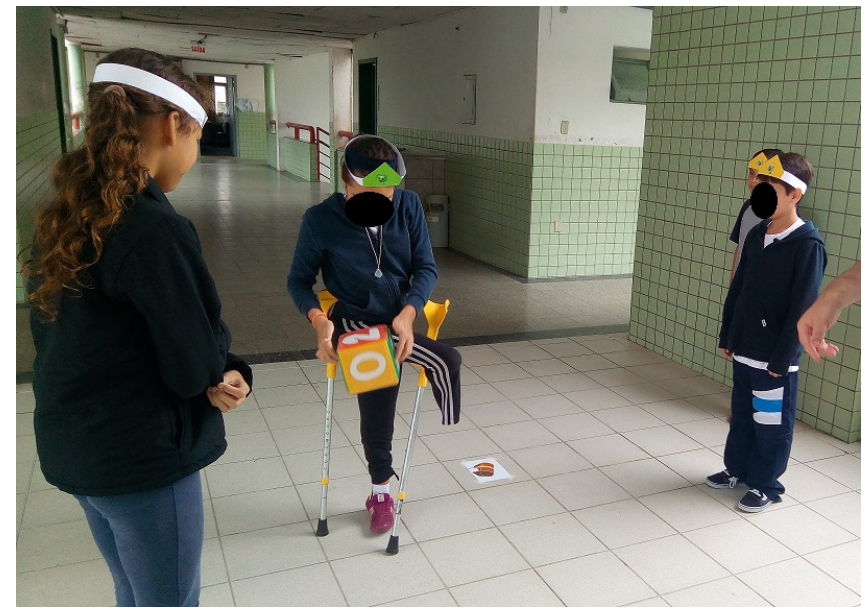

Figura 3. Tabuleiro Vivo na atividade

\subsection{Ordenação de cartas}

A atividade de ordenação de cartas, diferente das atividades anteriores, é jogada individualmente. Cada jogador recebe um monte com uma quantidade de cartas sendo que elas ordenadas representam alguma ação do cotidiano, como: colocar a louça na mesa, comer e lavar a louça; e, tomar banho e se vestir. Na Figura 4 tem-se duas crianças realizando a atividade.

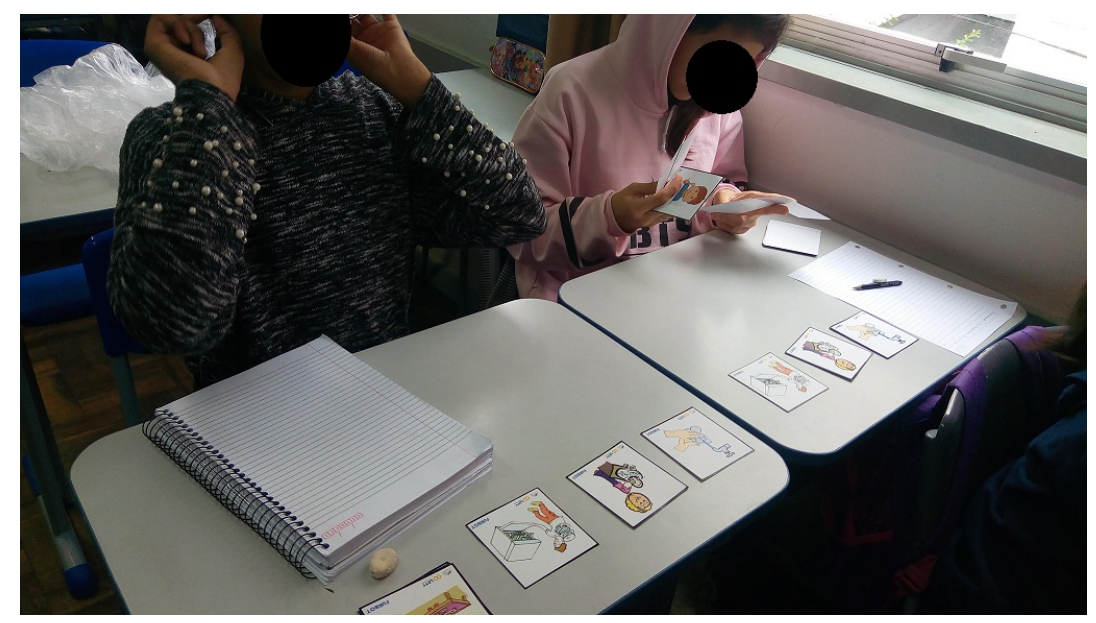

Figura 4. Ordenação de cartas

Como pode-se observar na figura, para resolver a atividade a criança deve ordenar a sequência correta das ações seguindo um raciocínio lógico. Na atividade, cada uma das crianças deveria resolver as duas sequências do cotidiano (lavar louça e tomar banho).

Ao final da atividade, a criança chamava o monitor para que este conferisse se a sequência estava correta. A partir dos conceitos apresentados deste jogo, pode-se afirmar que a atividade também trabalha questões do pensamento computacional como a sequência de passos e a composição de passos em um problema (que seria o inverso da decomposição).

Nesta atividade foram coletadas as respostas das crianças para análise posterior, 
VIII Congresso Brasileiro de Informática na Educação (CBIE 2019)

Anais dos Workshops do VIII Congresso Brasileiro de Informática na Educação (WCBIE 2019)

afim de verificar se elas realizam a sequência correta das atividades cotidianas com base na interpretação das cartas. Ainda, para aquelas que erravam a sequência, questionou-se o que foi interpretado pela carta, para que pudesse ser validado se a interpretação realizada se encaixava na sequência desenvolvida.

\subsection{Identificação de bugs}

A quarta atividade também é realizada de forma individual. $\mathrm{O}$ aluno recebe cinco folhas, contendo cada uma a sequência de passos de uma atividade cotidiana, sendo elas: dormir; ir para a aula; ligar o computador; comer; e tomar banho. Acontece que, na sequência apresentada há passos que estão trocados, como por exemplo: ao dormir você deve deitar e então fechar os olhos e a folha apresenta que ao dormir você fecha os olhos e então deita. Dessa forma, o aluno deve identificar as inconsistências apresentadas nessas sequências, ou seja, os bugs. A Figura 5 apresenta as crianças realizando a atividade.

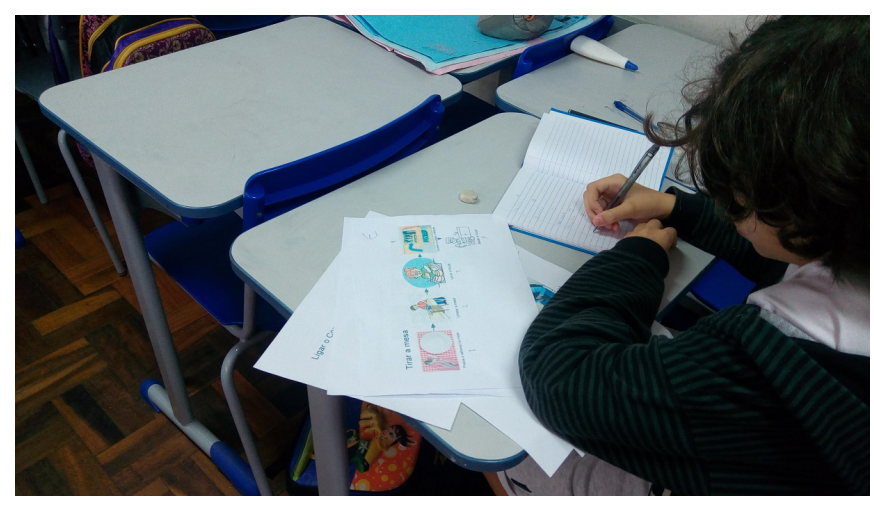

Figura 5. Ordenação de cartas

Para economizar as folhas da atividade, o aluno deve escrever em seu caderno qual o bug encontrado. Ao final de cada atividade, o aluno deve chamar o monitor para conferir se a identificação do bug está correta.

Assim como na atividade anterior, foram coletadas as respostas de cada criança com o objetivo de avaliar se elas obtinham a resposta correta com base em sua interpretação.

\section{Resultados e Discussões}

As quatro atividades foram projetadas para serem aplicadas igualmente nas quatro turmas, de $2^{\circ}$ ao $5^{\circ}$ ano do ensino fundamental na Escola Pedro II. Sabe-se que as atividades poderiam ser produzidas de forma distinta por faixa etária, contudo, como em nenhuma das turmas houve o ensinamento prévio sobre o pensamento computacional, optou-se pela utilização das mesmas atividades para todas as turmas.

Com relação a primeira atividade do jogo de tabuleiro, no tempo da atividade cada equipe conseguiu jogar de duas a três vezes. Observou-se que a medida em que as rodadas iam avançados, as crianças tomavam mais conhecimento a respeito das regras do jogo e a medida em que as movimentações eram realizadas, elas tomavam decisões mais sábias ao utilizar suas cartas. Por exemplo, no princípio acontecia da criança jogar a carta andarNorte () ; e na mesma rodada a carta andarSul () ; . Jogando essas duas 
VIII Congresso Brasileiro de Informática na Educação (CBIE 2019)

Anais dos Workshops do VIII Congresso Brasileiro de Informática na Educação (WCBIE 2019)

cartas o seu peão ficaria na mesma posição, contudo a criança jogava a carta para eliminar cartas de sua mão. Ao entender que poderia trocar as cartas com o monte, ao invés de jogalas, as crianças começaram a tomar decisões mais sábias. Ainda, elas foram instruídas que quanto menor a quantidade de cartas, mais eficiente será seu código-fonte final produzido. Assim, elas passaram a pensar antes de utilizar uma carta ou de troca-la com o monte. Além disso, observou-se que ao trocar cartas com o monte, as crianças pensavam quais cartas utilizariam em uma jogada futura para guarda-las para uso posterior.

Em relação as diferentes faixas etárias, nesta atividade percebeu-se que as crianças de $2^{\circ}$ e $3^{\circ}$ ano jogavam uma carta por vez, enquanto as crianças a partir do $4^{\circ}$ ano compreenderam que poderiam jogar mais cartas na sua jogada. Ainda, as crianças menores cometeram mais vezes a situação relatada anteriormente de jogar duas cartas que a mantém na mesma posição, porém, após a explicação pelo monitor, elas aprenderam e conseguiram realizar as jogadas corretamente.

Como mencionado anteriormente, ao finalizar o jogo, o monitor da atividade verificava se as cartas jogadas estavam corretas de acordo com o caminho que foi percorrido. A maioria das crianças observavam a execução na primeira vez e ao terminarem um segundo jogo executavam esses passos sozinhas, conferindo umas das outras se o peão tinha se movimentado de acordo com as cartas utilizadas. Com isso praticou-se a lógica sequencial, a decomposição do problema em partes (sendo elas as cartas) e a codificação do algoritmo.

Em relação a segunda atividade do tabuleiro humano, percebeu-se ser uma atividade mais lúdica. Nesta atividade as crianças se divertiam mais, contudo, também aprendiam sem perceber. As crianças treinaram principalmente a tomada de decisão e o planejamento estratégico para então tomar a ação. Também incentivou-se o trabalho em equipe, uma vez que se iniciavam com quatro robôs que tinham que fugir do Alien e alcançar o tesouro.

Relacionando a faixa etária para esta segunda atividade, percebeu-se que as crianças menores (até o $3^{\circ}$ ano), jogaram o jogo de forma mais lúdica, não se preocupando com a estratégia, ou seja, não se preocupavam em qual casa ir para fugir ou pegar o inimigo. Já as crianças a partir do $4^{\circ}$ ano, a medida em que compreendiam melhor o jogo, tomavam decisões mais sábias ao realizar seus movimentos.

A terceira atividade da ordenação das cartas de forma geral foi simples para todas as crianças de todas as faixas etárias envolvidas. Houve poucos erros de lógica na construção das sequências e, ainda, a maioria dos erros cometidos eram por interpretação errônea da carta. Percebeu-se que no após a explicação, elas conseguiam compreender o que fazer na atividade. Algumas crianças demoraram mais tempo do que outras para chegar a solução lógica, contudo, todas conseguiram. Essa atividade estimulou o raciocínio lógico e a construção de uma sequência cotidiana podendo ser representada posteriormente por um algoritmo. Também trabalhou-se a abstração, uma vez que as cartas representavam situações cotidianas através de uma única imagem.

Por fim, a quarta atividade da identificação dos bugs treinou também habilidades de abstração e decomposição de problemas, além do reconhecimento de padrões, sendo estes vindos do mundo real aplicados por meio da sequência. Embora essa atividade foi bem semelhante a atividade anterior, ela foi um pouco mais difícil para as crianças de $2^{\circ}$ 
VIII Congresso Brasileiro de Informática na Educação (CBIE 2019)

Anais dos Workshops do VIII Congresso Brasileiro de Informática na Educação (WCBIE 2019)

e $3^{\circ}$ ano sendo que nem todas conseguiram completar as cinco questões corretamente. A maioria dos erros cometidos foram por falta de atenção, pois, ao serem questionadas pelo monitor do motivo da resposta, logo elas percebiam que estava incorreta e se justificavam corrigindo o problema. Isso pode ter ocorrido pelo fato de que nesta atividade o problema é apresentado como um todo e o aluno deve extrair as informações mentalmente para então coloca-la em uma ordem lógica novamente.

Ao final das quatro estações, ainda houve um tempo de debate com cada turma para que as crianças percebessem algumas das habilidades praticadas. O que chamou a atenção, é que várias crianças destacaram que aprenderam que é necessário pensar antes de agir, a pensar para tomar decisões e ainda que é importante trabalhar em equipe. Embora elas não tenham a percepção clara dos fatores do pensamento computacional, estes fatores auxiliaram para que elas pudessem levar lições para o seu dia a dia.

\section{Considerações Finais}

O projeto de extensão tem como objetivo introduzir o pensamento computacional nas escolas de ensino fundamental da região. Para isso, realizou-se como atividade introdutória rotações por estações contendo quatro estações sendo estas relatadas no artigo.

Percebeu-se que com a atividade em forma de estações, pode-se trabalhar de formas diferenciadas habilidades do pensamento computacional sendo a a abstração, algoritmos, decomposição e reconhecimento de padrões. Ainda, em uma forma lúdica, as crianças foram introduzidas a estes conceitos sem ter a noção exata do que eles significam, mas sim, vivenciando-os na prática a partir de cada estação.

Dessa forma, entende-se que a atividade das quatro estações em forma de rotação estimulou as crianças a participarem e introduziu algumas das habilidades do pensamento computacional que podem ser trabalhadas de outras formas posteriormente. Ainda, a computação desplugada permite que as habilidades sejam praticadas em qualquer espaço de qualquer escola, sem que ela tenha uma laboratório de informática, permitindo uma ampliação na divulgação do conhecimento destas habilidades.

Logo, pretende-se aplicar a dinâmica em outros grupos de crianças, além de disponibilizar essas atividades para que qualquer escola ou grupo possa utilizar e aplicar em seu ambiente.

\section{Referências}

CIEB (2018). Currículo de referência em tecnologia e computação. http:// curriculo.cieb.net.br/curriculo.

de Paula, B. H., Valente, J. A., e Burn, A. (2014). O uso de jogos digitais para o desenvolvimento do currículo para a educação computacional na inglaterra. Currículo sem Fronteiras, 14(3):46-71.

Guarda, G., Gonçalves, C. D. S., Cunha, L. R. R., e Goulart, I. (2018). O circuito quatro desafios: Atividade lúdica apoiada pelo pensamento computacional. In Anais dos Workshops do VII Congresso Brasileiro de Informática na Educação (CBIE 2018). Brazilian Computer Society (Sociedade Brasileira de Computação - SBC).

Nishida, T., Kanemune, S., Idosaka, Y., Namiki, M., Bell, T., e Kuno, Y. (2009). A cs unplugged design pattern. SIGCSE Bull., 41(1):231-235. 
VIII Congresso Brasileiro de Informática na Educação (CBIE 2019)

Anais dos Workshops do VIII Congresso Brasileiro de Informática na Educação (WCBIE 2019)

Wing, J. M. (2006). Computational thinking. Commun. ACM, 49(3):33-35.

Zanetti, H., Borges, M., e Ricarte, I. (2013). Proposta de atividades para o desenvolvimento do pensamento computacional no ensino fundamental. In Anais do XXVII Simpósio Brasileiro de Informática na Educação (SBIE 2013). Sociedade Brasileira de Computação - SBC.

Zanetti, H., Borges, M., e Ricarte, I. (2016). Pensamento computacional no ensino de programação: Uma revisão sistemática da literatura brasileira. In Anais do XXVII Simpósio Brasileiro de Informática na Educação (SBIE 2016). Sociedade Brasileira de Computação - SBC. 